\title{
Nanomaterials and Energy Storage in a Glance: a Review
}

\author{
Mustafa Abdallh*,1, Zainab Hussain ${ }^{2}$, Hamsa Thamer ${ }^{1}$, Ali Abd Ali¹, Emad Yousif ${ }^{1}$ and \\ Salam Mohammed ${ }^{3}$
}

\author{
${ }^{1}$ Department of Chemistry, College of Science, Al-Nahrain University, Baghdad, Iraq \\ ${ }^{2}$ Department of Chemistry, College of Science, Misan University, Misan, Iraq \\ ${ }^{3}$ Department of Chemical and Petrochemical Engineering, College of Engineering and Architecture, \\ University of Nizwa, Nizwa, Oman
}

\begin{tabular}{ll}
\hline \multicolumn{1}{c}{ Article's Information } & \multicolumn{1}{c}{ Abstract } \\
\hline Received: & The challenge to provide a powerful instrument with a high energy conversion is \\
$27-02-2021$ & of a great importance to our modern society, not only in terms of conversion but \\
Accepted: & in high-capacity storage derived by the increase for energy demand. In addition, \\
$22-06-2021$ & the environmental impact of these new technologies to create a green and \\
Published: & sustainable environment. One of these green technologies is the use of dye- \\
$27-06-2021$ & sensitized solar cells to produce energy and lithium-ion batteries to store the \\
Keywords: & generated energy. The need for high electronic mobility and high surface volume \\
Nanomaterials & and activity, nano metal oxide was investigated as alternative or a new material \\
Energy storage & in generation and conversion of energy. For this purpose, many metal oxides \\
$\mathrm{ZnO}_{\mathrm{TiO}}$ & were explored especially Zinc oxide (ZnO) and titanium oxide (TiO $\left.{ }_{2}\right)$ due to their \\
\hline
\end{tabular}

DOI: $10.22401 /$ ANJS.24.2.04

*Corresponding author: mustafa.abdallh@ced.nahrainuniv.edu.iq

\section{Introduction}

Nanomaterials (NM) have been exploited in various research areas, including energy storage and conversion and highlighted in the literature [1]. Their physical and chemical properties are significantly varying from conventional materials. With regards to the energy storage and conversion, semiconducting NM, such as metal-oxide semiconductors have been lately engaged in the scientific application and mostly implemented in energy storage devices. Namely, using nanomaterials in the latest development of photovoltaic cells as well as lithium batteries. To eliminate or lower weak properties of standard electrodes via introducing the above materials, will reduce the recombination of charge rates and increase the charge carrier mobility as well. Recently, researchers are focusing on metal-oxide nanostructure (MON) due to their availability on the earth, composition, unique shape, physical and chemical properties [2]. Thus, they have found their way in solar cells, photolysis of water to produce and store hydrogen, light emitting devices, water treatment, energy saving batteries, transistors, fuel cells, sensors and detectors [3-19]. Transition Metal oxides has strong ferromagnetism properties in addition to relatively high curie temperature making them good candidates for the use in data storage, read and write equipment's [20]. Spintronics devices uses metal oxides such as $\mathrm{ZnO}, \mathrm{Al}_{2} \mathrm{O}_{3}$ and $\mathrm{TiO}_{2} . \mathrm{SnO}_{2}$ nanomaterial is used in sensors design due to their high sensitivity to detect low concentration of flammable gases [22]. ITO as an optical transparent material with relatively high conductivity in addition to tin oxide makes them ideal materials to be used in manufacturing flat panel displays [23]. In respect with cost of manufacturing, $\mathrm{ZnO}$ is considered a good replacement of ITO in addition to easier rechargeability characteristics [24] In addition to the above, some MONs such as $\mathrm{ZnO}$ and $\mathrm{TiO}_{2}$ recently found their way into more extensive research due to their

Chemical synthesis convenience. The introduction of the metal oxides to the solar cell's construction may influence the active mesoporous layer and optimizing the efficiency of the dye-sensitized solar cells (DSSCs). Although of the big achievement in the design and construction of such solar cells, the capabilities of these cells are still limited due to the charge separation issues as well as the transport with in the electrodes. In addition to difficulties in repository of energy in rechargeable batteries. The application of nanomaterials can be very advantageous in enhancing the devices efficiency. i.e., traditional lithium-ion batteries may increase their specific capacity via introducing MON to the design which may lead to reduce the possibility of batteries catching fire.

\section{Energy Production and Storage Devices}

The traditional way of energy supply starts with generation of the energy as a first step, then carry on to the smallscale use: this may result in a drastic loss of energy 


\section{Al-Nahrain Journal of Science}

ANJS, Vol.24 (2), June, 2021, pp. 21-26

through the distribution network, this can be seen in many energy productions such as nuclear and hydroelectric. On the other hand, the application in different large class system such as mobile system where the need for energy is less due low power devices or in far areas like rural zone in which theirs is no electrical net is provided. The solution to this kind of problems is to set a local energy production system. For this reason, the large energy production can successfully link with circulation hotspots. It was revealed a few years ago that extensive implementation of distributed generation means in power systems can significantly enhance the creation of a reasonably clean, and reliable energy [25]. researchers are interested in the design of low energy harnessing system which is usually dispersed and no one exploit it in producing energy, such as smart windows and solar facades. The design of this system takes in to the consideration of high efficiency in energy conversion as well as other factors like flexibility or its mechanical and aesthetics properties which are essential in the construction of the solar cells. Managing the energy supply can be relied on two approaches. First, the design of the device itself in order to work correctly by limiting the constant supply of fuel, i.e., fuel cells, super capacitors and batteries. Such devices are categorized as non-regenerative power supplies.

The second approach is a regenerative device such as thermoelectric devices, solar panels and mechanical harvesters which does not need any fuel to run. The technology applied in energy resources distribution are illustrated in Figure 1, [25].

Great number of devices is being used for storing and generating energy. DSSCs are designed to generate energy while the lithium-ion batteries are designed to store the generated energy. Those devices are attracting a great attention in terms of ease manufacturing in addition to the availability and cheap materials involved in the construction of such devices. In the next two sections, DSSCs and Li-ion batteries will be the main focus, [27].

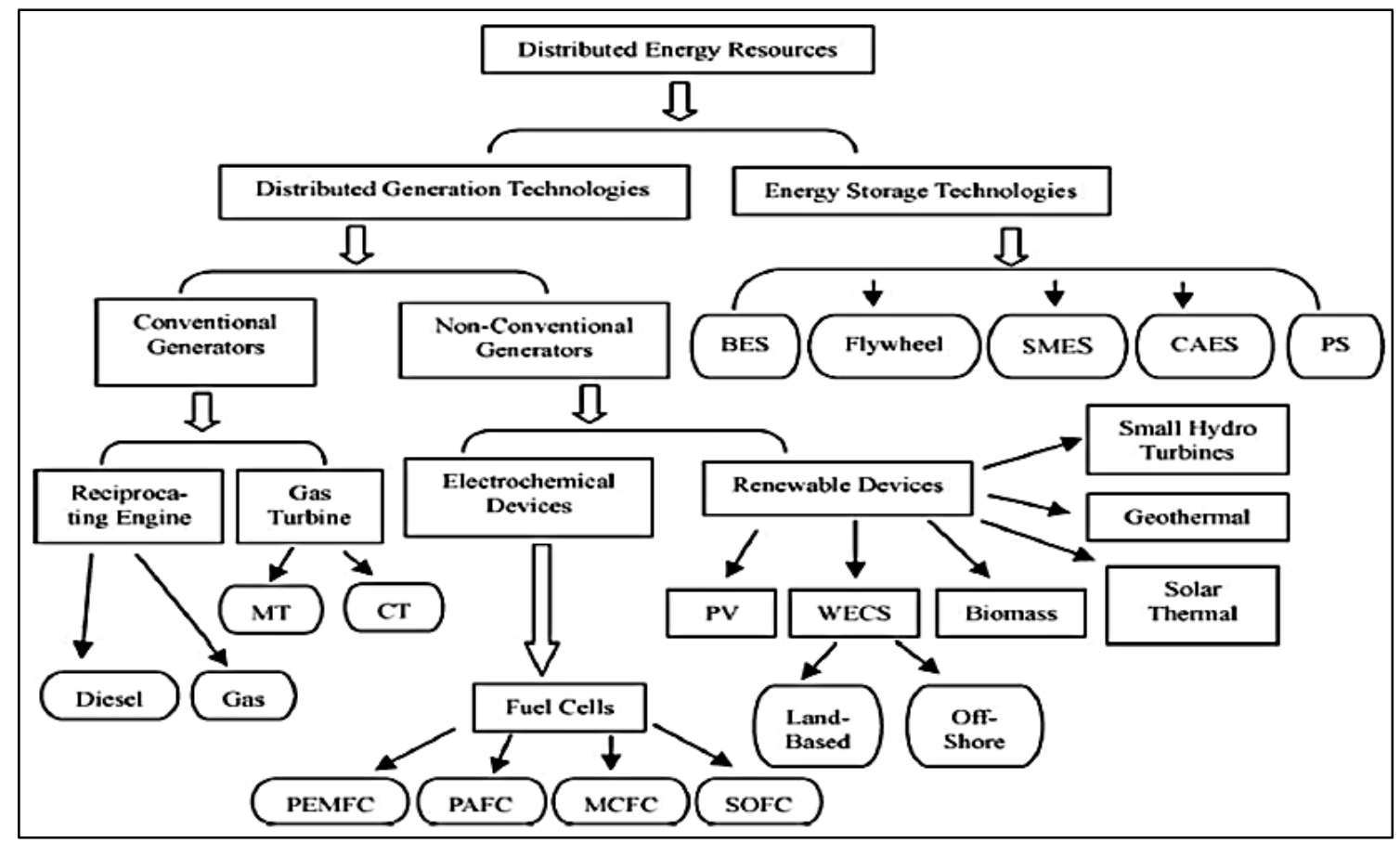

Figure 1. The technology applied in energy resources distribution [25].

\subsection{DSSCs}

The seminal work of O'Regan and Grätzel in 1991 in creating DSSCs grabbed much attention as solar harvesters [28] after a long work in this field started in 1970s. Solar harvesters can be generated using accessible organic materials and non-toxic and cheap semiconducting materials via implementing simple technologies as possible. Additionally, evading elevated temperatures and high-vacuum treatments and apply it in roll-to-roll technology [29]. Moreover, DSSCs can work effectively indoor applications [30]. As the name of these solar cells suggests, dyes are used for the construction of the metal- oxide strongly supported by the significant decrease in the recombination of the electron-hole process. Electrolyte, solvents containing the dissolved redox materials, provide the electrons causing a dye electrical regeneration. It has the ability to pass through the pores of the nanostructure closing to the sensitizer material fabricating 3D junction. The ionic electrolyte has the ability to gain the hole from the dye after oxidation. Iodide/triiodide diffusion redox couple increased the efficiency up to $11 \%[31,32]$. Electron cross the nanomaterial layer is integrated where the diffused electrons are with external circuit. The chemical structure does not change or transformed to 


\section{Al-Nahrain Journal of Science}

ANJS, Vol.24 (2), June, 2021, pp. 21-26

another form with in the cell. Graetzel during its experiments reported that the efficiency of the polycrystalline anatase film to harvest the sunlight and convert it to current is increased from 1.25 up to $7.9 \%$ via $\mathrm{TiO}_{2}$ nanostructured mesoporous layer $[33,34]$.

The increase of the surface area will increase the exposed area to sunlight which leads to increase the cell efficiency. A single layer of the dye tethered to the surface effect the ability to absorb photons, the small amount of the absorbed photons can affect the efficiency of the cell due to the short cross-section area on the electrode surface. The introduction of the nanomaterials may lead to enhance the exposed area of the dye. Subsequently, the efficiency of the DSSC in generating energy is increased too (Figure 2).

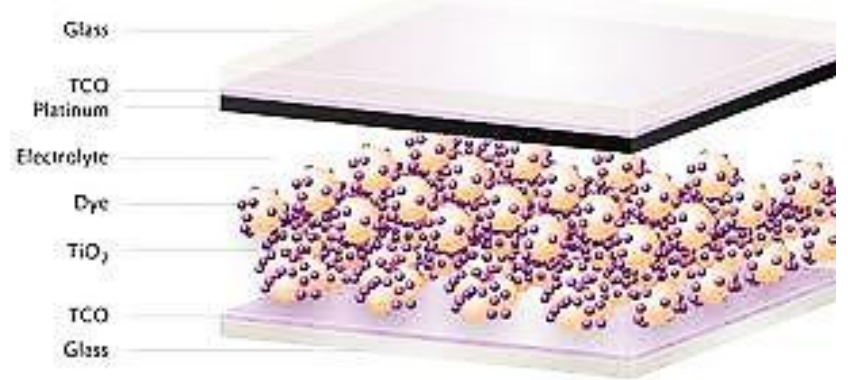

Figure 2. DSSC cell structure [35].

\subsection{Lithium ion microbatteries}

Lithium-ion batteries (LIB) have as an essential invention in contemporary electrochemical materials and applications. The science and technology of these batteries have been primarily explained and discussed in the literature [36,37].

A marketable LIB (Figure 3) usually constructed of negative electrode such as graphite and positive electrode embraces lithium layered not as lithium metal but as lithium metal oxide like $\mathrm{LiCoO}_{2}$. Lithium-ion electrolyte is used in the isolation of the cell electrodes. In most cases, the separator is immersed in ethylene-diethyl carbonate solution of $\mathrm{LiPF}_{6}$.

In LIBs, the active materials design includes electronic and ionic conductors to work correctly. The current flow greatly affected by the mobility of the electronic and ionic $\left(\mathrm{Li}^{+}\right)$conductors, hence affecting the power supplied to the device. Therefore, the increase in the surface area will increase the efficiency of the battery via application of nanostructured material in the fabrication of the electrode. Also, the reduction of the distance of the ionic travel as well as the electronic conduction will be very effective in the device performance. Nano materials can perfectly tolerate this criterion of insertion of the ions by changing the size of the surface of the electrode which enhance the working cycle of the lithium ion based batteries.

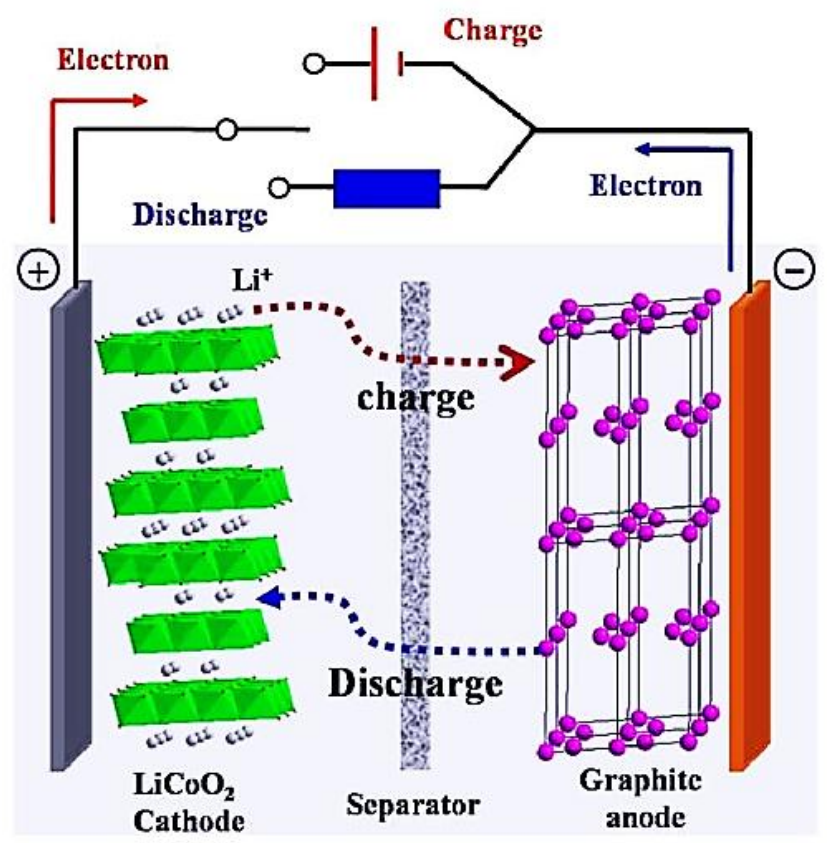

Figure 3. Sketched picture of a $\mathrm{LiB}$ [38].

Appling nano scale materials in the design of LIBs would be very useful in different aspects:

(a) Enhancing the life cycle performance of the batteries by better absorbing of the strain of $\mathrm{Li}^{+}$, Figure 4.

(b) Superior performance in comparison to micrometer sized particle as nano electrode have the ability to undergo new reactions.

(c) Nano layered electrode provides a high surface area of electrode/electrolyte contact, subsequently increase the rate of charge/discharge.

(d) Allowing operating with low electronic conductivity with high power as the cross section9 of electronic and $\mathrm{Li}^{+}$transport is reduced.

\section{Energy Applications of Nanostructured $\mathrm{TiO}_{2}$}

The unique properties of $\mathrm{TiO}_{2}$ make it a good candidate as a solution for the increase demand for the energy. The low energy band gap of nanostructured $\mathrm{TiO}_{2}$ plays an important role in converting the visible light to energy alone is not sufficient. The molecular design of the dye sensitizer must take in consideration to enhance the DNSCs efficiency. This may support the water splitting photolytically which can participate in the solving the demand for energy problems. The process does not give a high quantum yield makes it hard to increase the scalability of the process. The improvement in the process of redox reaction in water splitting in addition to the electron-hole reconnecting. 


\section{Al-Nahrain Journal of Science}

ANJS, Vol.24 (2), June, 2021, pp. 21-26

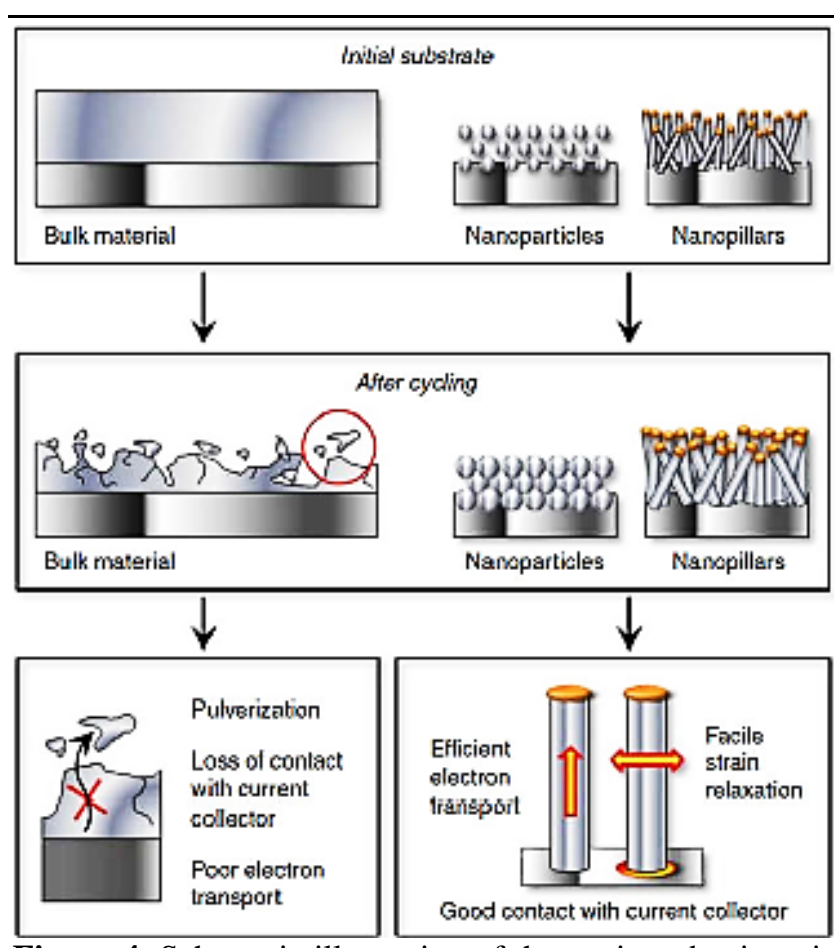

Figure 4. Schematic illustration of the strain reduction via application of nanostructured materials to improve the workability of LIBs [39].

Problems can contribute to the water splitting process and increase the final yield. Also, the storage of hydrogen within the nano structure materials needs to increase in order to meet the requirements for storing hydrogen [40].

\section{Dye-synthesized Nano Crystalline Solar Cells / $\mathrm{TiO}_{2}$}

Typically, DNSCs fabrication comprises two sheets of glass. These sheets (conducting glass) are coated with Florine doped in tin oxide as a thin layer. A colloidal $\mathrm{TiO}_{2}$ is coated on one of the glass sheets of 20-40 nm thickness as a thin layer. The mesoporous layer is created by sintering the film at $400{ }^{\circ} \mathrm{C}$ in which the produced layer has a porosity of about $50 \%$ [41]. Different methodologies are applied to produce the mesoporous film such as, $\mathrm{TiO}_{2}$ colloid treated hydrothermally or sol-gel processing methodologies. The $\mathrm{TiO}_{2}$ coating on the glass sheet was sensitized with organic dye such as cis-bis (isothiocyanate) bis (2,2-bipyridyl-4, 4-dicarboxylato)-ruthenium (II) bipyridyl-4, 4-dicarboxylato)-ruthenium (II) bistetrabutylammonium. The dye selected for the sensitizing must have high absorption coefficient in the visible region. Hence, the solar light in the visible area has enough energy to excite the electrons to the conduction band (CB). In addition, good chemosorption of the dye on the surface of the substrate resulted in a good adhesion characteristic between the semiconductor and the dye. Thus, the molecular structure design may include phosphonate or carboxylate groups to increase the interactions between the $\mathrm{TiO}_{2}$ and the dye [42]. The second glass sheet (conducting glass) comprises of a platinum layer coated on the surface by either electrochemical deposition or sputtering. A hot melt polymer gasket was used to hold the glass sheets together where the electrolyte (usually iodide/tri-iodide redox couple) is loaded via tiny puncture in the glass coated with platinum followed by locking this puncture after finishing the electrolyte loading. Figure 5 give a schema to illustrate the manufacturing process of DNSCs.

\section{Functionality of Dye-Sensitized Nano Crystalline Solar Cell}

Nano crystalline mesoporous $\mathrm{TiO}_{2}$ film represent the core of the DNSC bound to a charge transfer dye in a single layer to its surface [43]. The application of the light rays on the transparent electrode can excites the dye to the $\mathrm{CB}$ of the $\mathrm{TiO}_{2}$ until they find their way to the glass substrates through the random interconnection of the oxide particles [44]. The external circuit provides the redox electrolyte with the electrons. The dye will gain the electrons from the electrolyte to restore its original state, in which the electrons in $\mathrm{CB}$ of the oxidized dye were locked by iodide. On the other hand, reduction of tri-iodide at the counterelectrode will recover the iodide original state. Electrical circuit is finished with the electrons traveling via the external load. Generally, the generated power in the solar cells as a result of exposure to light does not involve any chemical transformation permanently $[41,43]$. Figure 5 (a) represents the schematic of the operation of the DNSCs, and the summary of the regeneration process is shown in Figure 5 (b).

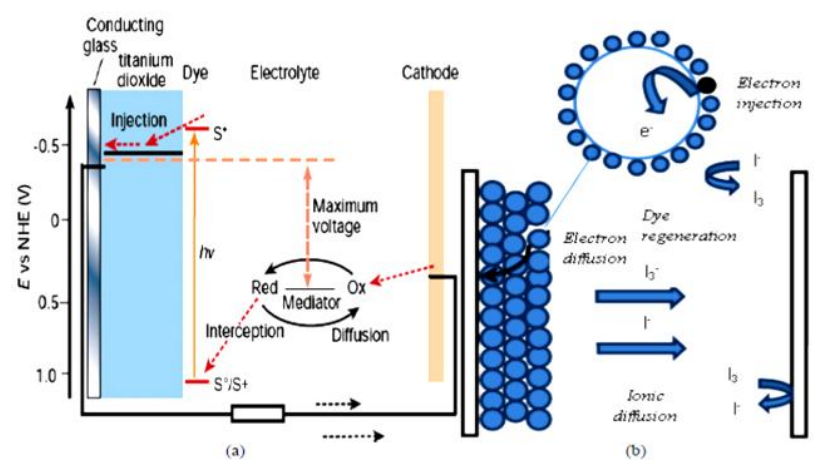

Figure 5. (a), and (b) Schematic of the operation of DNSC and Regenerative cycle in DNSC.

\section{Conclusion}

In conclusion, nano materials and particularly metal oxide semiconductors have attracted much attention due to their contribution in harnessing light and converting it into useful energy. Research is still ongoing to develop these materials to undergo optimal energy production and storage. This review needs some overview from time to time to assess efforts being made and demonstrating prospects for future directions.

\section{References}

[1] Dou Y.; Zhang L.; Xu X.; Sun Z.; Liao T. and Dou S. $\mathrm{X}$.; "Atomically thin non-layered nano materials for 


\section{Al-Nahrain Journal of Science}

ANJS, Vol.24 (2), June, 2021, pp. 21-26

energy storage and conversion"; Chemical Society Reviews., 46(23), 7338-7373, 2017.

[2] Tianyou Z.; Xiaosheng F.; Meiyong L.; Xijin X.; Haibo Z.; Bando Y. and Dmitri G. A.; "Comprehensive review of one-dimensional metal-oxide nanostructure photodetectors", Sensors. 9, 6504-6529, 2009.

[3] Poizot P.; Laruelle S.; Grugeon S.; Dupont L. and Tarascon J.; "Nano-sized transition-metal oxides as negative-electrode materials for lithium-ion batteries", Nature, 407, 496-9, 2000.

[4] Huang H.; Kelder E. and Schoonman J.; "Graphitemetal oxide composites as anode for li-ion batteries"; J. Power Sources, 97/98, 114-117, 2001.

[5] Asamoto M.; Miyake S.; Sugihara K. and Yahiro H.; "Improvement of $\mathrm{Ni} / \mathrm{SDC}$ anode by alkaline earth metal oxid addition for direct methane-solid oxide fuel cell"; Electrochem. Comm., 11, 1508-1511, 2009.

[6] Mamak M.; Coombs N. and Ozin G.; "Self-assembling solid oxide fuel cell materials: mesoporous yttriazirconia and metal-yttria-zirconia solid solutions"; J. Am. Chem. Soc. 122, 8932-8939, 2000.

[7] Snaith H. and Mende L.; "Advances in liquid electrolyte and solid state dye sensitized solar cells"; Adv. Mater. 19, 3187-3200, 2007.

[8] Gratzel M.; "Photo electrochemical cells", Nature. 414, 338-344, 2001

[9] Sun B. and Sirringhaus H. "Solution-processed zinc oxide field-effect transistors based on self-assembly of colloidal nanorods"; Nano let. 5, 2408-13, 2005.

[10] Aric`o A.; Bruce P.; Scrosati B.; Tarascon J. and Van-Schalkwijk W.; "Nanostructured materials for advanced energy conversion and storage devices"; Nat. Mater. 4, 366, 2005.

[11] Kim B.; Ryu Y.; Lee T. and White H.; "Output power enhancement of $\mathrm{GaN}$ light emitting diodes with pp-type $\mathrm{ZnO}$ hole injection layer", Appl. Phys. Lett. 94, 103506, 2009.

[12] Won I. and Yi G.; "Electroluminescence in $\mathrm{n}-\mathrm{ZnO}$ Nanorod Arrays Vertically Grown on p-GaN", Adv. Mater. 16, 87-90, 2004.

[13] Im J.; Park S.; Kim T. and Lee Y.; "Hydrogen storage evaluation based on investigations of catalytic properties of metallmetal oxides in electrospun carbon fibers", Int. J. Hydrogen Energy., 34, 33823388, 2009.

[14] Wan Q.; Lin C.; Yu X. and Wang T.; "Roomtemperature hydrogen storage characteristics of $\mathrm{ZnO}$ nanowires"; Appl. Phys. Lett. 84, 124, 2004.

[15] Hepel M. and Hazelton S.; "Photoelectrocatalytic degradation of diazo dyes on nanostructured $\mathrm{WO}_{3}$ electrodes"; Electochim Acta. 50, 5278-5291, 2005.

[16] Guo Y.; Hu J. and Wan L.; "Nanostructured materials for electrochemical energy conversion and storage devices" Adv. Mater. 20, 2878, 2008.

[17] Rout C. Hegde, M. Govindaraj A. and Rao C.; "Ammonia sensors based on metal oxide nanostructures", Nanotech, 18, 205504, 2007.
[18] Zhang W.; "A review of the electrochemical performance of alloy anodes for lithium-ion batteries"; J. Power Sources. 196, 13, 2011.

[19] Li Y.; Valle S. F.; Yamada I.; Delaunay J.; "High performance UV detector made of ultra-long zno pridging nanowires"; Nanotech, 20, 045501, 2009.

[20] Yang Y.; Ruan G.; Xiang C.; Wang G. and Tour J. M.; "Flexible three-dimensional nanoporous metalbased energy devices", J. Am. Chem. Soc. 136, 61876190, 2014.

[21] Barick K.; Aslam M.; Dravid V. and Bahadur D.; "Self-aggregation and assembly of size-tunable transition metal doped $\mathrm{ZnO}$ nanocrystals"; J. Phys. Chem. C 112, 15163, 2008.

[22] Fallah H.; Ghasemi M.; Hassanzadeh A. and Steki. H.; "The effect of deposition rate on electrical, optical and structural properties of tin-doped indium oxide (ITO) films on glass at low substrate temperature", Phys. B 373, 274-279, 2006.

[23] Kim H.; Kim J.; Park M. and Im S. "Photoelectric, stoichiometric and structural properties of $\mathrm{n}-\mathrm{ZnO}$ film on p-Si"; Thin Solid Films, 93-98, 398, 2001.

[24] Yang Q.; Jiang X.; Guo X.; Chen Y. and Tong L. "Hybrid structure laser based on semiconductor nanowires and a silica microfiber knot cavity", Appl. Phys. Lett., 94, 101108, 2009.

[25] Akorede M.; Hizam H. and Pouresmaeil E.; "Distributed energy resources and benefits to the environment. Renew", Sust. Energ. Rev., 14, 724734, 2010.

[26] Vasiliev M.; Alameh K. and Nur-E-Alam M. "Spectrally-selective energy-harvesting solar windows for public infrastructure applications", Appl. Sci., 8, 849. 2018.

[27] Fürer S. O.; Milhuisen R. A.; Kashif M. K.; Raga S. R.; Acharya S. S.; Forsyth C. and Funston A. M. "The performance determining role of Lewis bases in dye sensitized solar cells employing copper bisphenanthroline redox mediators", Adv. Energy Mat., 2002067, 2020.

[28] Hagfeldt A.; Lindström H.; Södergren S. and EricLindquist S.; "Photoelectrochemical studies of colloidal $\mathrm{TiO}_{2}$ films: The effect of oxygen studied by photocurrent transients", Journal of Electroanalytical Chemistry, 381 , 39-46. 1995.

[29] Hashmi G.; Miettunen K.; Peltola T.; Halme J.; Asghar I.; Aitola Toivola K. and Lund P.; "Review of materials and manufacturing options for large area flexible dye solar cell"; Renew. Sust. Energ. Rev., 15, 3717-3732, 2011.

[30] Sacco A.; Rolle L.; Scaltrito Tresso L. and Pirri, C.; "Characterization of photovoltaic modules for lowpower indoor application"; Appl. Energy, 102, 12951302, 2013.

[31] Bessho T.; Zakeeruddin S.; Yeh C. Y.; Diau E. G. Grätzel M.; "Highly efficient mesoscopic dye sensitized solar cells based on donor-acceptor 


\section{Al-Nahrain Journal of Science}

ANJS, Vol.24 (2), June, 2021, pp. 21-26

substituted porphyrins", Ange. Chemie Int. Ed., 49, 6646-6649, 2010.

[32] Yella A.; Lee H.; Tsao H.; Yi C.; Chandiran A.; Nazeeruddin M.; Diau E.; Yeh C.; Zakeeruddin S. and Grätzel M.; "Porphyrin-sensitized Solar cells with cobalt (II/III)-based redox electrolyte exceed 12 percent efficiency", Science, 4, 629-34, 2011.

[33] Vlachopoulos N.; Liska P.; Augustynski J. and Gratzel M.; "Very efficient visible light energy harvesting and conversion by spectral sensitization of high surface area polycrystalline titanium dioxide films", J. Am. Chem. Soc., 110, 1216-1220, 1988.

[34] O'Regan B.; Grätzel M. and Fitzmaurice D.; "Optical electrochemistry I: steady-state spectroscopy of conduction-band electrons in a metal oxide semiconductor electrode", Chemical Physics Letters. 183, 89-93, 1991.

[35] Shauddin S. M.; "Comparison among Various Emerging PV Cells with History, Current Status and Future Challenges", Energy and Power, 3, 91-105, 2013

[36] Arico A.; Bruce P.; Scrosati B.; Tarascon J. and Van Schalkwijk W.; "Nanostructured Materials for Advanced Energy Conversion and Storage Devices"; Nat. Mater., 4, 366-77, 2005.

[37] Van Schalkwijk W. and Scrosati B.; "Advances in Lithium-Ion Batteries. Kluwer/Plenum”; J. Am. Chem. Soc., 125, 3670-3671, 2003.

[38] Gert B.; Maarten M.; Jelle S.; Noshin O.; Lieselot V. and Joeri Van M.; "Cost Projection of State of the Art Lithium-Ion Batteries for Electric Vehicles Up to 2030" Energies, 10, 1314, 2017

[39] Nyankson E.; Agyei-Tuffour B.; Asare J.; Annan E.; Rwenyagila E.; Konadu D.; Yaya A. and DodooArhin D.; "Nanostructured $\mathrm{TiO}_{2}$ And Their Enrgy Applications-A Review"; ARPN Journal of Engineering and Applied Sciences, 8, 871-886, 2013.

[40] Nyankson E.; Agyei-Tuffour B.; Asare J.; Annan E.; Rwenyagila E.; Konadu D.; Yaya A. and DodooArhin D.; "Nanostructured $\mathrm{TiO}_{2}$ and their energy applications-A review", ARPN Journal of Engineering and Applied Sciences, 8, 871-886, 2013.

[41] Peter L.; "Dye synthesized nano crystalline solar cells", Physical Chemistry Chemical Physics, 9, 2630-2642, 2007.

[42] McEvoy J. and Gratzel, M.; "Die synthesized nano crystalline solar cells"; J. of Photochem. and Photobio. A: Chemistry, 143, 117-136, 2006.

[43] Gratzel M.; "Review Dye synthesized solar cells", Journal of Photochemistry and Photobiology C: Photochem. Rev. 4, 145-153, 2003.

[44] Martinu L. and Poltras, J.; "Plasma deposition of optical films and coatings: a review", Vacuum Science Technology, A. 18, 2619-2645, 2000. 